\title{
Inovasi Model Bisnis Inkubasi dan Kolaborasi dalam Meningkatkan Kinerja UMKM Surabaya di Era 4.0
}

\author{
Anang Subardjo ${ }^{* 1}$, Mia Ika Rahmawati \\ ${ }^{1,2}$ Akuntansi, Sekolah Tinggi Ilmu Ekonomi Indonesia (STIESIA) Surabaya, Indonesia \\ Email: ${ }^{1}$ anangsubardjo@stiesia.ac.id, ${ }^{2}$ miaikarahmawati@ stiesia.ac.id
}

\begin{abstract}
Abstrak
UMKM memiliki kontribusi yang besar dalam perekonomian Indonesia, agar tetap dapat bersaing dengan perubahan lingkungan yang cepat utamanya perkembangan teknologi informasi di era 4.0, maka dibutuhkan inovasi model bisnis bagi UMKM. Oleh karena itu Tujuan Penelitian ini adalah merumuskan Inovasi model bisnis inkubasi dan kolaborasi pada Usaha Kecil, Mikro dan Menengah (UMKM) 4.0 dalam upaya memperkuat dan menopang UMKM khususnya di era digitalisasi 4.0. Penelitian ini melakukan pendekatan kualitatif dengan melakukan identifikasi masalah, observasi, pendampingan dan Focus Group Discussion (FGD) dengan pemilik UMKM. Analisis data dilakukan dengan memetakan model bisnis UMKM 4.0 dengan Canvas Analysis sebagai bagian dari strategi bisnis SME dengan menganalisis kelemahan dan kekuatan UMKM ditinjau dari 9 faktor. Dari Analisis Canvas, maka UMKM membutuhkan Strategi Inkubasi Bisnis yang inovatif didasarkan pada Strategi Kolaborasi tiga pemangku kepentingan plus satu; Pemerintah, Perguruan Tinggi, Koperasi, dan pemanfaatan teknologi informasi. Pemerintah memberikan kemudahan sertfikasi PIRT, Perguruan Tinggi memberikan pelatihan laporan keuangan yang bankable, Koperasi Skomill sebagai Inkubator memberikan mentoring bisnis, pengurusan legalitas usaha, branding dan Pemasaran baik offline maupun online di Tokopedia sehingga UMKM bisa naik kelas. Inovasi model bisnis Inkubasi dan kolaborasi dapat memperkuat dan menopang UMKM di era digitalisasi 4.0 sehingga UMKM bukan lagi menjadi Superman akan tetapi Superteam. Dengan desain Inovasi Model Bisnis Inkubasi UMKM 4.0, pemilik UMKM mendapatkan arahan yang jelas dalam menjalankan usahanya sehingga dapat bersaing dan meningkatkan kinerjanya.
\end{abstract}

Kata kunci: Inkubasi UMKM 4.0, Inovasi Model Bisnis, Keberlanjutan UMKM, Penguatan UMKM.

\begin{abstract}
SMEs have a major contribution to the Indonesian economy, in order to remain competitive with rapid environmental changes, especially the development of information technology in the 4.0 era, business model innovation is needed for SMEs. Therefore, the purpose of this study is to formulate an incubation and collaboration business model innovation for Small, Micro and Medium Enterprises (SMEs) 4.0 in an effort to strengthen and support SMEs, especially in the era of digitalization 4.0. This study uses a qualitative approach by identifying problems, observing, assisting and Focus Group Discussion (FGD) with SME owners. Data analysis was carried out by mapping the SME 4.0 business model with Canvas Analysis as part of the SME business strategy by analyzing the weaknesses and strengths of SMEs in terms of 9 factors. From the Canvas Analysis, SMEs need an innovative Business Incubation Strategy based on a Collaboration Strategy of three plus one stakeholder; Government, Universities, Cooperatives, and the use of information technology. The government provides convenience for PIRT certification, Universities provide training on bankable financial reports, the Skomil Cooperative as an Incubator provides business mentoring, business legal management, branding and marketing both offline and online at Tokopedia so that SMEs can advance to class. Incubation and collaboration business model innovations can strengthen and support SMEs in the 4.0 digitalization era so that SMEs are no longer Superman but Superteams. With the design of the SME Incubation Business Model 4.0 Innovation, SME owners get clear directions in running their business so they can compete and improve their performance.
\end{abstract}

Keywords: Business Model Innovation, Incubation SME 4.0, SME Sustainability, Strengthening SME

\section{PENDAHULUAN}

UMKM merupakan pilar terpenting dalam Perkembangan Perekonomian di Indonesia, ini dapat 
dilihat dari besarnya kontribusi terhadap PDB, Penyerapan tenaga kerja dan Investasi. Berdasarkan data kementerian Koperasi pada tahun 2019, jumlah UMKM mencapai 65.465.497 setara 99,99\% dari total unit usaha di Indonesia memiliki kontribusi terhadap PDB sebesar 60,51\% atau senilai 8.573,89 triliun rupiah dan penyerapan tenaga kerja sebesar $67 \%$ dari total tenaga kerja yang ada serta menghimpun Investasi sebesar 60,4\% dari total investasi di tahun 2020 (Kementerian KUKM, 2021). Besarnya jumlah umkm tersebut menunjukkan masih sedikitnya UMKM naik kelas secara berjenjang dan bersaing secara global. Kelemahan utamanya adalah ketrampilan manajerial dan teknis (Rahman, 2010). Bahkan Menteri Keuangan menyatakan UMKM tidak dapat bersaing secara global adalah tidak memiliki legalitas usaha (NPWP dan Haki), Akses yang sulit dalam pembiayaan, pendampingan dalam tata kelola, minimnya standar produksi, pemasaran tersebut diperparah adanya Pandemi Covid 19 yang berdampak terpuruknya penjualan para pelaku UMKM di Indonesia. Survey yang dilakukan ABDSI menunjukkan $36,7 \%$ responden menyatakan tidak ada penjualan, $60 \%$ menyatakan mengalami penurunan sedangkan yang mengalami kenaikan hanya 3,3\% (Jayani, 2020).

Persoalan tersebut juga terjadi pada UMKM di Surabaya seperti: tidak terstandarisasi produk, kemasan yang alah kadarnya, tidak melakukan pencatatan pembukuan secara teratur serta pemasaran sehingga membutuhkan pendampingan secara intensif untuk mendesain kembali inovasi model bisnis yang dilakukan oleh UMKM di Era industri 4.0. Era Industri 4.0 mencirikan (i) mencapai peluang inovasi dan digitalisasi, (ii) memperbesar proses bisnis, (iii) mendefinisikan inovasi model bisnis.

Langkah strategis yang dilakukan dalam mendesain inovasi model bisnis dengan strategis model canvas yang terdiri dari 9 elemen utama (Osterwalder, et al., 2011). Berdasarkan hal diatas rumusan masalahnya adalah bagaimana UMKM dapat mengatasi kekurangan kemampuan manajerial dan teknisnya dengan Inovasi model bisnis inkubasi 4.0? Penelitian ini bertujuan untuk mengevaluasi implementasi strategi bisnis dan merekomendasikan inovasi model bisnis untuk UMKM khususnya di industri makanan dan minuman. Model bisnis menggambarkan bagaimana sebuah perusahaan melakukan bisnis (Osterwalder et al, 2011). Studi sebelumnya menemukan bahwa sebagian besar bisnis memiliki keragaman aktivitas dalam bisnis - keragaman model bisnis. Perbedaan ini seringkali tidak dapat dijelaskan secara ketat oleh satu model bisnis inti (Lindgren, 2013). Penelitian yang terkait dengan Inovasi Model Bisnis pada UMKM adalah sebagai berikut:

Tabel 1. Penelitan terdahulu Inovasi Model Bisnis pada UMKM

\begin{tabular}{|c|c|c|c|}
\hline No & Referensi & Judul & Hasil \\
\hline 1 & $\begin{array}{l}\text { (Hidayat, } \\
\text { Pangaribuan, et al., } \\
2020 \text { ) }\end{array}$ & $\begin{array}{l}\text { Business model } \\
\text { innovation on smes: A } \\
\text { literature review }\end{array}$ & $\begin{array}{l}\text { Hasil penelitian adalah memberikan konsep } \\
\text { tentang pendorong keberhasilan Inovasi } \\
\text { model bisnis dipengaruhi faktor eksternal, } \\
\text { alat dan cara melakukan perbaikan. }\end{array}$ \\
\hline 2 & $\begin{array}{l}\text { (Müller \& Däschle, } \\
\text { 2018), }\end{array}$ & $\begin{array}{l}\text { Business model } \\
\text { innovation of industry } \\
\text { 4.0 solution providers } \\
\text { towards customer } \\
\text { process innovation }\end{array}$ & $\begin{array}{l}\text { UMKM telah terbukti fokus pada manfaat } \\
\text { yang terkait dengan operasional dan produksi } \\
\text { dari Industri } 4.0 \text { daripada manfaat strategis. }\end{array}$ \\
\hline 3 & (Rosmadi, 2021) & $\begin{array}{l}\text { Inovasi r dan } \\
\text { Kreativitas Pelaku } \\
\text { Usaha UMKM di Era } \\
\text { Covid-19 }\end{array}$ & $\begin{array}{l}\text { Hasil penelitian, diperoleh bahwa kualitas } \\
\text { sumber daya manusia (SDM) berupa inovasi } \\
\text { dan kreativitas sangat mendukung } \\
\text { keberlangsungan kegiatan UMKM. }\end{array}$ \\
\hline 4 & $\begin{array}{l}\text { Safar, Sopko, } \\
\text { Bednar, \& Poklemba, } \\
\text { 2018) }\end{array}$ & $\begin{array}{lr}\text { Concept of } & \text { SME } \\
\text { business model for } \\
\text { industry } & 4.0 \\
\text { environment } & \end{array}$ & $\begin{array}{l}\text { Perusahaan jauh lebih efektif setelah } \\
\text { menerapkan visi platform 4.0. perusahaan } \\
\text { akan membutuhkan investasi awal yang } \\
\text { berpotensi lebih tinggi untuk perangkat lunak } \\
\text { standar dan kinerja tinggi perangkat keras. }\end{array}$ \\
\hline
\end{tabular}


5 (Zambon, Egidi, Applied research Rinaldi, \& Cividino, towards Industry 4.0: 2019) Opportunities for SMEs

6 (Zahoor \& Tabbaa, 2020)
Al- Inter-organizational collaboration and SMEs' innovation: A systematic review and future research directions
UMKM mengalami kesulitan terhadap kerangka kerja 4.0 karena beberapa alasan. Akibatnya, tekadnya adalah untuk memajukan pengaturan kerangka kerja 4.0, dibutuhkan infrastruktur pendukung untuk memfasilitasi UMKM menghadapi tantangan masa depan dan memanfaatkan peluang revolusi industri keempat.

Hasil penelitian menunjukkan bahwa heterogenitas dalam inovasi sebagai hasil muncul karena dua alasan: faktor pendukung yang berbeda mungkin diperlukan untuk membangun kolaborasi antar organisasi; dan mekanisme moderasi dan mediasi diperlukan untuk menangkap manfaat inovasi yang ditawarkan oleh UMKM.

\subsection{Canvas Model Bisnis}

Business Model Canvas (BMC) adalah konsep konsep model bisnis yang mewakili strategi bisnis dan proses dalam sebuah organisasi. Analisis BMC adalah analisis model yang menguraikan bagaimana sebuah organisasi menciptakan, menyediakan, dan menangkap nilai-nilainya. Model bisnisnya bisa dijelaskan melalui sembilan blok yang menunjukkan bagaimana bisnis menghasilkan uang. Sembilan blok dibagi menjadi empat utama bidang, yaitu pelanggan, penawaran, infrastruktur, dan keuangan kelangsungan hidup (Osterwalder et al., 2010).

a. Segmen pelanggan

Adalah kelompok orang atau organisasi yang berbeda dan perusahaan bertujuan untuk dijangkau dan dilayani. Pebisnis harus membuat keputusan tentang segmen mana yang harus dilayani dan segmen mana yang diabaikan. Setelah keputusan ini dibuat, model bisnis dirancang dengan hati-hati sesuai dengan kebutuhan pelanggan tertentu (Osterwalder et al., 2010).

b. Proposisi Nilai

Adalah kumpulan produk dan layanan yang menciptakan nilai untuk Segmen Pelanggan tertentu. Nilai Proposisi menjadi alasan mengapa pelanggan beralih kepada perusahaan yang lain. Hal ini memecahkan masalah pelanggan atau memenuhi kebutuhan pelanggan. (Osterwalder, et al., 2010).

c. Saluran menuju pelanggan

Menjelaskan bagaimana perusahaan berkomunikasi dengan dan mencapai Segmen Pelanggan untuk menyampaikan Proposisi Nilai (Osterwalder et al., 2010).

d. Hubungan dengan Pelanggan

Menggambarkan jenis hubungan perusahaan menetapkan dengan Segmen Pelanggan tertentu (Osterwalder et al., 2010).

e. Aliran Pendapatan

Mewakili uang tunai yang dihasilkan perusahaan dari setiap Segmen Pelanggan. (Osterwalder et al., 2010).

f. Sumber daya kunci

Menjelaskan tentang aset terpenting yang diperlukan untuk membuat pekerjaan model bisnis. Sumber daya ini memungkinkan perusahaan untuk membuat dan menawarkan Nilai Proposisi, mencapai pasar, menjaga hubungan dengan segmentasi pelanggan untuk, mendapatkan pendapatan (Osterwalder et al.,2010).

g. Kegiatan utama

Menjelaskan tentang hal terpenting yang harus dilakukan perusahaan bekerja berdasarkan model bisnisnya. Setiap model bisnis mendukung sejumlah Aktivitas Utama. Ini adalah tindakan terpenting yang harus diambil perusahaan untuk beroperasi dengan sukses (Osterwalder et al., 2010).

h. Kemitraan Utama 
Menjelaskan tentang jaringan pemasok dan mitra yang membuat model bisnis berjalan. Perusahaan menempa kemitraan karena berbagai alasan, dan kemitraan menjadi landasan dari banyak model bisnis. Perusahaan membuat aliansi untuk mengoptimalkan model bisnis mereka, mengurangi risiko, atau memperoleh sumber daya. (Osterwalder et al., 2010).

i. Struktur biaya

Menjelaskan semua biaya yang muncul sebagai akibat dioperasikannya model bisnis ini. Mulai dari upaya mewujudkan segmen pelanggan, proposisi nilai, melalui channel yang tepat, key resources, dan key activities yang handal, semuanya membutuhkan biaya. Struktur biaya dipengaruhi oleh strategi perusahaan yang dipilih, apakah mengutamakan biaya rendah atau mengutamakan manfaat istimewa. (Osterwalder et al.,2010).

\subsection{Strategi Kolaborasi}

Norris, et. al (2010) mendefinisikan strategi kolaborasi sebagai pendekatan kolektif yang disengaja untuk mengatasi masalah atau isu melalui pengembangan pengetahuan bersama, merancang solusi inovatif dan menempa perubahan konsekuensial. Di sisi lain, kolaborasi membantu perusahaan untuk mencegat teknologi perusahaan lain serta menutup kesenjangan keterampilan lebih cepat dibandingkan dengan pengembangan internal. Kolaborasi strategis mencakup berbagai jenis kolaborasi mulai dari keterlibatan rendah, hubungan pendanaan hingga keterlibatan tinggi, modal usaha patungan. Kolaborasi membantu perusahaan untuk berhasil. Kesadaran UMKM memberikan akses ke kompetensi inti yang berbeda yang seringkali unik untuk setiap organisasi dan sektor dalam membangun manfaat di antara UMKM melalui akses ke jaringan; organisasi bisnis memahami kondisi lokal, hubungan dengan komunitas lokal, reputasi dan kredibilitas yang lebih tinggi. Oleh karena itu, kolaborasi strategis menyiratkan kontribusi keterampilan, sumber daya, dan keahlian.

\section{METODE PENELITIAN}

Penelitian ini memuat beberapa tahapan dalam melakukan penelitian. Berawal dari urgensi Inovasi model bisnis, penelitian ini bertujuan untuk mengembangkan Inovasi Model Bisnis untuk UMKM di Surabaya berkolaborasi dengan Skomill Surabaya khususnya di sektor makanan dan minuman. Penelitian dilakukan pada bulan Juli sampai September 2021 dengan melakukan pendampingan terhadap beberapa UMKM di Surabaya. Analisis Canvas Model Bisnis digunakan sebagai alat dan dijelaskan lebih detail untuk strategi inovasi baru UMKM.

Sebagai metode penelitian, identifikasi masalah merupakan langkah awal untuk mendapatkan tujuan penelitian. Kemudian studi pustaka dilakukan dengan mengumpulkan teori dan informasi yang terkait dengan penelitian dari berbagai sumber seperti buku teks, jurnal, laporan dan penelitian sebelumnya sebagai data sekunder. Penelitian ini menggunakan pendekatan kualitatif berdasarkan observasi lapangan, pendampingan terhadap UMKM di Surabaya sebagai studi kasus dan Focus Group Discussion (FGD) dengan para pemilik UMKM. Pendekatan kualitatif digunakan untuk menyajikan analisis data yang membantu memetakan Inovasi model bisnis UMKM yang ada. Akhirnya, inovasi model bisnis adalah dikembangkan sebagai rekomendasi yang mencakup rencana implementasi strategi untuk meningkatkan kinerja dari UMKM.

\section{HASIL DAN PEMBAHASAN}

Berdasarkan hasil pendampingan dan Focus Group Discusion (FGD) terhadap UMKM komunitas produk minuman dan makanan di Surabaya diperoleh informasi yang bisa dijelaskan berdasarkan mapping strategi Canvas Bisnis Model (CBM) yang diperkenalkan Osterwerder, et al, (2010), yang akan digunakan untuk menggambarkan, mengevaluasi, dan mencari cara-cara yang efektif dalam menerapkan model bisnis UMKM, yang dapat diuraikan sebagai berikut:

a. Segmen pelanggan

Mengacu pada Osterwalder et al., (2010), karena UMKM produk makanan dan minuman di

Surabaya memiliki segmen berpenghasilan menengah ke bawah dikarenakan pelaku UMKM belum mampu mengemas produk dengan baik dan kualitas produk yang belum terstandarisasi baik dari segi hygne maupun tempat produksi. Wajar jika produk yang djual kebanyakan laku di pelanggan 
di ekonomi rendah. Persoalan tersebut akan berdampak pada elemen lain seperti Proposi Nilai, hubungan dengan pelanggan. Jika persoalan tersebut tidak segera ditangani, maka pelaku umkm tidak pernah naik kelas.

b. Proposisi Nilai

Mengacu pada Osterwalder et al., (2010) penciptaan nilai pelanggan bisa dapat dilakukan dalam bentuk kuantitatif (harga yang murah dan cepat dalam pengiriman) maupun kualitatif (desain dan kemasan). Nilai Proposisi menjadi alasan mengapa pelanggan beralih kepada perusahaan yang lain. Hal ini memecahkan masalah pelanggan atau memenuhi kebutuhan pelanggan. (Osterwalder, et al., 2010). Untuk proposisi nilai yang dimiliki oleh komunitas UMKM produk makanan dan minuman di Surabaya adalah baru sebatas kuantitatif (harga dan kecepatan pengiriman) sedangkan nilai pelanggan dalam bentuk kualitatif masih belum terwujud. Bagi pelanggan menengah kebawah dan sangat sensitive terhadap harga, maka nilai pelanggan dengan harga murah dan cepat pengiriman akan diterima dengan baik, akan tetapi hal ini tidak berlaku bagi bagi konsumen dengan perekonomian menengah keatas lebih suka diberi nilai pelanggan yang bersifat kaulitatif, seperti: kemasan (packaging) yang bagus dan rasa yang terstandarisasi meskipun harganya naik.

c. Saluran menuju pelanggan

Mengacu pada Osterwalder et al., (2010) bagaimana perusahaan berkomunikasi dengan dan mencapai Segmen Pelanggan untuk menyampaikan Proposisi Nilai. Usaha yang dilakukan UMKM untuk mendekatkan dengan Segmen Pelanggan melalui Word of Mouth (WOM) sebagai sarana untuk memperkenalkan dan menjual produknya. Metode ini ditempuh sekaligus acara pengiklanan yang gratis produk UMKM dan dapat melakukan efisiensi biaya. Cara lain yang bisa ditempuh adalah dengan meningkatkan penjualan dan mengakuisisi pelanggan baru.

d. Hubungan dengan Pelanggan

Mengacu pada Osterwalder et al., (2010) mempertahankan hubungan dengan pelanggan adalah faktor untuk memperoleh pendapatan dalam jangka panjang. Karena jika UMKM melakukan hubungan dengan pelanggan secara baik, maka potensi mendapatkan pendapatan akan kosisten, untuk mempertahankan pelanggan yang sudah ada dan mencari pelanggan baru akan dapat meningkatkan penjualan dan hasilnya adalah pendapatan yang dapat memberikan tingkat laba.

e. Aliran Pendapatan

Mengacu pada Osterwalder et al., (2010) pendapatan yang diterima oleh UMKM cenderung stabil karena segmen yang dibidik menengah kebawah dan tidak melakukan periklanan yang bersifat berbayar. Ini sangat membahayakan dalam jangka panjang karena UMKM tidak memiliki dana taktis jika terjadi kondisi dan situasi seperti pandemik covid 19 yang berdampak pelaku umkm mengalami financial distress bahkan mengalami kebangkrutan.

f. Sumber daya kunci

Mengacu pada Osterwalder et al., (2010) sumberdaya kunci UMKM pada produk makanan dan minuman adalah sumberdaya manusia dalam mengelola produk karena sifatnya yang masih tradisional dan tangiable asset (resep makan dan minuman) yang tidak mudah untuk ditiru atau diimitasi. Artinya jika ada pesaing, maka ada pembedanya baik dari segi kualitas bahan baku, proses produksi sampai produk jadi.

g. Kegiatan utama

Mengacu pada Osterwalder et al. (2010) hal terpenting yang harus dilakukan UMKM dalam melakukan model bisnis. Tindakan terpenting yang harus diambil UMKM untuk beroperasi dengan sukses adalah mengelola bahan baku, memproduksi dan menjualnya, kegiatan utama ini dilakukan untuk mendapatkan pendapatan yang memberikan laba bagi umkm agar tetap survive dan sustanaible.

h. Kemitraan Utama

Mengacu pada Osterwalder et al., (2010) maka Jaringan pemasok dan mitra yang membuat model bisnis berjalan. Perusahaan menempuh kemitraan karena berbagai alasan, dan kemitraan menjadi landasan dari banyak model bisnis. Perusahaan membuat aliansi untuk mengoptimalkan model bisnis mereka, mengurangi risiko, atau memperoleh sumber daya. UMKM memiliki kemitraan pemasok bahan baku adalah pedagang dipasar tradisional. 
i. Struktur biaya

Mengacu pada Osterwalder et al., (2010), maka pelaku UMKM memiliki struktur biaya yang tidak rumit, mulai dari biaya bahan baku, biaya tenaga kerja sampai menghasilkan pendapatan. Jika dilihat dari segmentasi pelanggan yang sensitif terhadap harga, maka yang dpilih umkm mengutamakan sturktur biaya yang rendah dari pada mengutama manfaat bagi pelanggan.

Rekomendasi inovasi model bisnis berdasarkan Canvas Bisnis Model tersaji dalam Tabel 2 di bawah ini.

Tabel 2. Analisis Canvas Bisnis Model

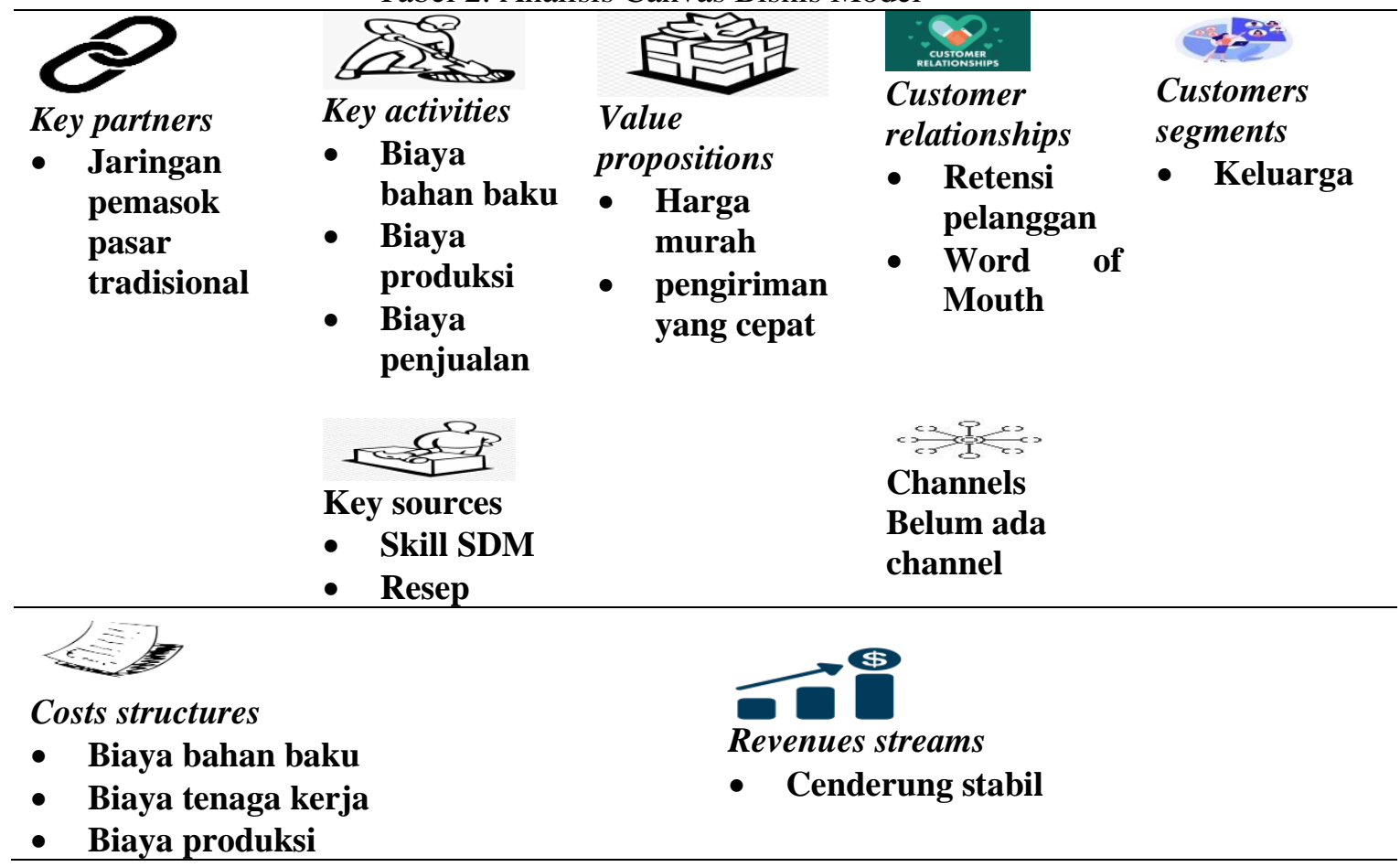

Berdasarkan model bisnis canvas, menunjukkan masih ada kelemahan manajerial dan teknis sehingga umkm akan tetap jalan ditempat atau tidak akan bisa berkembang. Untuk menjawab hal tersebut sebagaiamana dalam rumusan masalah, yaitu bagaimana UMKM dapat mengatasi kekurangan kemampuan manajerial dan teknisnya dengan Inovasi model bisnis inkubasi 4.0? untuk itu UMKM perlu mendesign kembali model bisnis dan strategi kolaborasi dengan koperasi Skomill (Sentral Komunitas Milineal) yang baru launching 27 Desember 2020 dengan menjadi anggota koperasi. Dengan masuknya UMKM di Koperasi Skomill selain mendapat pinjaman tanpa agunan dan menabung juga mendapatkan benefit berupa mentoring bisnis, pendampingan legalitas usaha, konsultasi branding dan pemasaran secara online melalui marketplace seperti Tokopedia dan media sosial serta mengikuti pameran UMKM yang dilaksanakan Skomill atau pihak-pihak lain yang berkolaborasi. UMKM dapat menempatkan produknya secara offline maupun online di Skomill. Seperti diketahui kelemahan dari UMKM adalah inovasi produk dari sisi packaging, branding dan pemasaran. Dengan Skomill bertindak sebagai inkubator bisnis dengan memberikan layanan dukungan operasi sampai kuat dan cukup dewasa bagi umkm untuk meninggalkan inkubator untuk tumbuh dan berkembang serta dapat menjadi inkubator bagi umkm yang masih jalan ditempat.

Implementasi strategi kolaborasi dapat digunakan untuk merancang solusi yang inovatif dan menempa perubahan konsekuensial serta membantu umkm dalam melakukan digitalisasi bisnis. (Norris, et. al, 2010) dengan demikian kesenjangan teknologi pada umkm dapat diminimalisasi utamanya dalam menghadapi Era industri 4.0 yang mengedepankan pencapaian peluang inovasi dan digitalisasi, memperbesar proses bisnis serta mendefinisikan inovasi model bisnis. Dengan demikian UMKM yang tergabung dalam Skomill dapat meningkatkan bersaing secara global. 
Berikut ini dapat digambarkan keunggulan yang diperoleh UMKM dengan berkolaborasi dengan Koperasi Skomill Surabaya:

a. Memudahkan akses kredit ke perbankan utamanya Bank BNI yang sudah menjalin kerjasama dengan Koperasi Skomill.

Koperasi Skomill menjadi penjamin bagi UMKM dalam melakukan kredit di Bank BNI. Untuk mendukung hal tersebut koperasi skomill membuat aplikasi GriyaSkomill yang isinya data lengkap UMKM dan data Transaksi harian UMKM sehingga Griyaskomill berfungsi untuk mendeteksi pendapatan harian dari para pelaku UMKM yang tergabung pada Koperasi Skomill. Dengan demikian akan mempermudah UMKM mendapat akses bisnis karena sudah dianggap bankable.

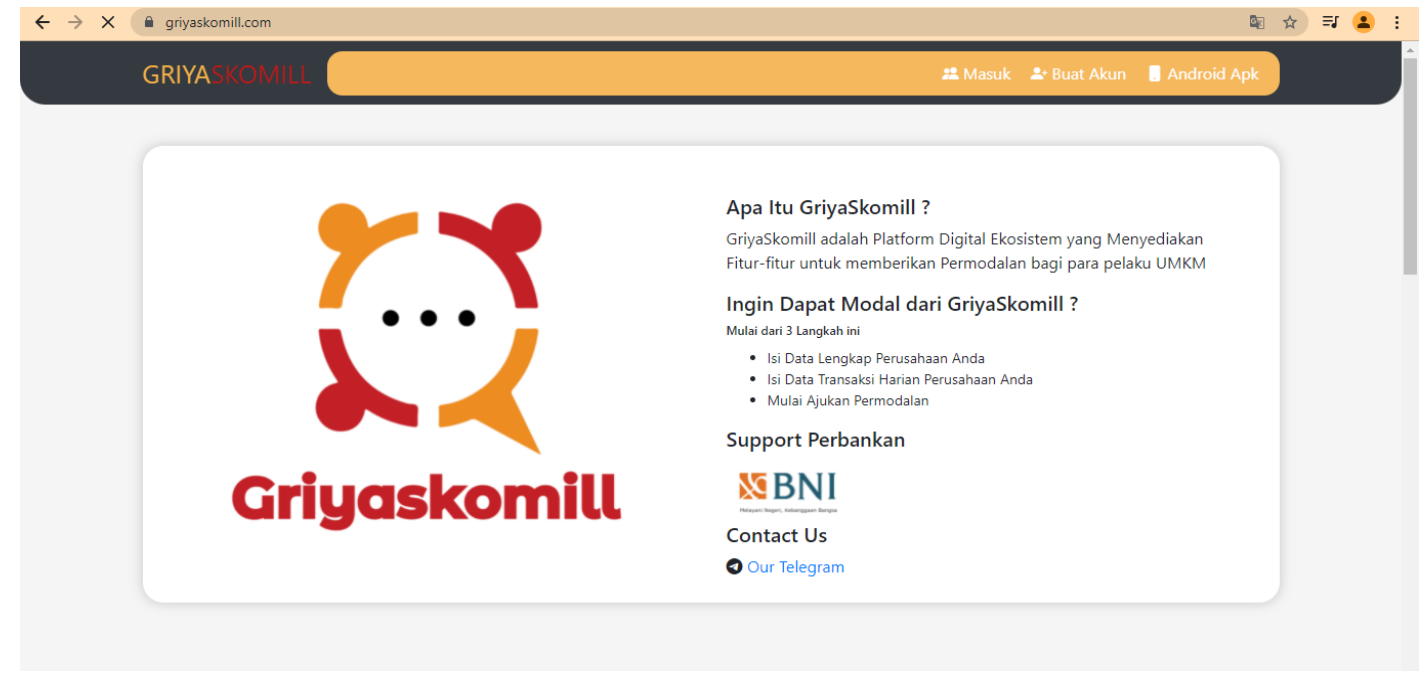

Gambar 1. Aplikasi Griyaskomill

b. Kelebihan dari Strategi Kolaborasi UMKM dengan Koperasi Skomill di bidang pemasaran dan penjualan secara online melalui Tokopedia.com.

Produk yang dijual dan dipasarkan sudah mendapatkan Sertifikat Produksi Pangan Industri Rumah Tangga (SPP-PIRT).

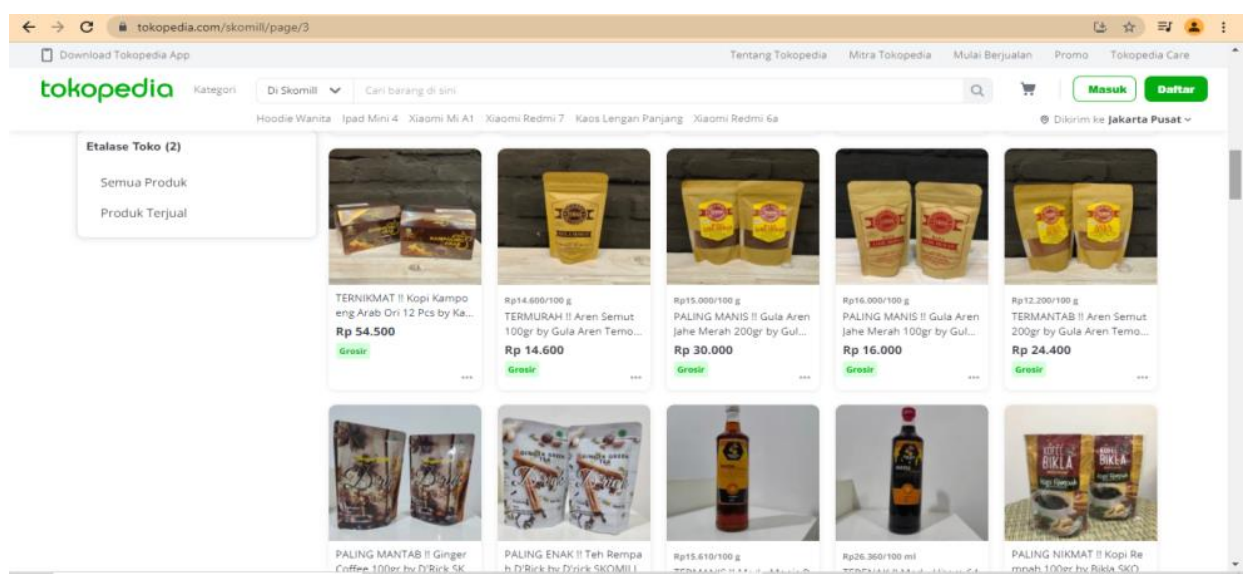

Gambar 2. Pemasaran dan Penjualan online produk UMKM di tokopedia

\section{KESIMPULAN}

UMKM merupakan pilar terpenting dalam Perkembangan Perekonomian di Indonesia, ini dapat dilihat dari besarnya jumlah dan kontribusi terhadap PDB, Penyerapan tenaga kerja dan Investasi, besarnya jumlah umkm menunjukkan ada kesadaran masyarakat dalam berwirausaha tetapi disatu sisi menunjukkan sulitnya UMKM naik kelas. Banyak persoalan yang umum dialami UMKM adalah 
rendahnya dalam inovasi produk utamanya dalam packaging, brand dan pemasaran serta laporan keuangan. Untuk perlu stimulus dan sentuhan pendampingan utamanya dalam menghadapi era industri 4.0 dan persaingan global.

Untuk itu dibutuhkan strategi kolaborasi dan inkubasi bisnis agar pelaku UMKM dapat naik kelas, yang selama ini produk UMKM selalu dianggap sebelah mata. Skomill selaku Koperasi tidak hanya menyediakan dana bagi anggotanya tetapi juga memberikan inkubasi bisnis baik tentang laporan keuangan, packaging, brand, pemasaran dan penjualan. Dengan demikian kelemahan yang selama ini dimiliki UMKM dapat tertutup sehingga UMKM yang tergabung dalam Skomill dimasa yang akan datang dapat bersaing secara global. Untuk itu dibutuhkan sinergitas Pemerintah, Koperasi dan UMKM.

\section{DAFTAR PUSTAKA}

Hidayat, D., Pangaribuan, C. H., Putra, O., \& Suci, A. (2020). Business model innovation on smes: A literature review. International Journal of Advanced Science and Technology, 29(5), 4426-4434.

Jayani, D. H. (2020). Penurunan Penjualan UMKM Imbas Pandemi Covid-19. Dkatadata.Co.Id, (April), 1. Retrieved from https://databoks.katadata.co.id/datapublish/2020/06/10/penurunan-penjualanumkm-imbas-pandemi-covid-19

Kementrian KUKM. (2021). Perkembangan Data Usaha Mikro, Kecil, Menengah, dan Usaha Besar. Www.Depkop.Go.Id, 2000(1), 1. Retrieved from http://www.depkop.go.id/data-umkm

Müller, J. M., \& Däschle, S. (2018). Business model innovation of industry 4.0 solution providers towards customer process innovation. Processes, 6(12), 1-20. https://doi.org/10.3390/pr6120260

Norris-Tirrell, D., \& Clay, J. A. (2010). Strategic collaboration in public and nonprofit administration: a practice-based approach to solving shared problems. American Society for Public Administration, 393. Retrieved from http://www.gbv.de/dms/sub-hamburg/615217540.pdf

Osterwalder, A., Pigneur, Y., Smith, A., \& Movement, T. (2011). Business Model Generation: A handbook for visionaries, game changers and challengers. In African Journal of Business Management (Vol. 5).

Rosmadi, M. L. N. (2021). Inovasi dan Kreativitas Pelaku Usaha UMKM di Era Covid-19. Jurnal IKRAITH Ekonomika, 4(2), 87-94.

Safar, L., Sopko, J., Bednar, S., \& Poklemba, R. (2018). Concept of SME business model for industry 4.0 environment. TEM Journal, 7(3), 626-637. https://doi.org/10.18421/TEM73-20

Zahoor, N., \& Al-Tabbaa, O. (2020). Inter-organizational collaboration and SMEs' innovation: A systematic review and future research directions. Scandinavian Journal of Management, 36(2), 101109. https://doi.org/10.1016/j.scaman.2020.101109

Zambon, I., Egidi, G., Rinaldi, F., \& Cividino, S. (2019). Applied research towards Industry 4.0: Opportunities for SMEs. Processes, 7(6), 1-8. https://doi.org/10.3390/pr7060344 